\title{
Immigration, acculturation, and preferred help-seeking sources for depression: comparison of five ethnic groups
}

Valeria Markova ${ }^{1 *}$, Gro M. Sandal ${ }^{2}$ and Ståle Pallesen ${ }^{2,3}$

\begin{abstract}
Background: Immigrants are more likely than the majority population to have unmet needs for public mental health services. This study aims to understand potential ethnic differences in preferred help-seeking sources for depression in Norway, and how such preferences relate to acculturation orientation.

Methods: A convenience sample of immigrants from Russia $(n=164)$, Poland $(n=127)$, Pakistan $(n=128)$, and Somalia ( $n=114)$, and Norwegian students $(n=250)$ completed a survey. The sample was recruited from social media platforms, emails, and direct contact. The survey consisted of a vignette describing a moderately depressed person. Respondents were asked to provide advice to the person by completing a modified version of the General Help-Seeking Questionnaire. The immigrant sample also responded to questions about acculturation orientation using the Vancouver Index of Acculturation Scale.

Results: Significant differences were found in the endorsement of traditional (e.g., religious leader), informal (e.g., family), and semiformal (e.g., internet forum) help-sources between immigrant groups, and between immigrant groups and the Norwegian respondent group. Immigrants from Pakistan and Somalia endorsed traditional help sources to a greater extent than immigrants from Russia and Poland, and the Norwegian student sample. There were no ethnic differences in endorsement of formal mental help sources (e.g., a medical doctor). Maintenance of the culture of origin as the acculturation orientation was associated with preferences for traditional and informal help sources, while the adoption of mainstream culture was associated with semiformal and formal help-seeking sources.
\end{abstract}

Conclusion: Ethnic differences in help-seeking sources need to be considered when designing and implementing mental health services.

Keywords: Depression, Ethnic groups, Minority groups, Acculturation, Help-seeking behavior, Immigrant, Refugees, Mental health services, Help-seeking intentions, Vignette methodology

\footnotetext{
*Correspondence: valeria.markova@uib.no

'Department of Pulmonology, Haukeland University Hospital, Bergen,

Norway

Full list of author information is available at the end of the article
}

(C) The Author(s). 2020 Open Access This article is licensed under a Creative Commons Attribution 4.0 International License, which permits use, sharing, adaptation, distribution and reproduction in any medium or format, as long as you give appropriate credit to the original author(s) and the source, provide a link to the Creative Commons licence, and indicate if changes were made. The images or other third party material in this article are included in the article's Creative Commons licence, unless indicated otherwise in a credit line to the material. If material is not included in the article's Creative Commons licence and your intended use is not permitted by statutory regulation or exceeds the permitted use, you will need to obtain permission directly from the copyright holder. To view a copy of this licence, visit http://creativecommons.org/licenses/by/4.0/ The Creative Commons Public Domain Dedication waiver (http://creativecommons.org/publicdomain/zero/1.0/) applies to the data made available in this article, unless otherwise stated in a credit line to the data. 


\section{Background}

Providing efficient mental health services for a growing immigrant population is a significant challenge for many countries. Acculturative stress, low socio-economic status, social isolation, and feelings of powerlessness in the country of settlement are factors that are recognized to increase the vulnerability of immigrants to mental health problems [1-4]. For refugees, trauma experienced before and during their flight may also have severe consequences for their mental health $[1,5,6]$. A nationwide cross-sectional study in Norway reported that immigrants had a higher likelihood of being frequent attenders at general practitioners (GP) than the native population. Problems related to mental health were one of the most common factors associated with frequent visits among immigrants from low- and middle-income countries [7]. While increased attention to access to mental healthcare has been seen among immigrants in recent years [5, 8, 9], epidemiological research from Norway and other European countries suggest underutilization of specialized mental health services among some immigrant groups compared to the native population $[1,2,8-11]$. The rate has been found to vary widely by country of origin $[12,13]$. This might imply that some immigrant groups have a higher proportion of untreated mental health problems than the rest of the population or that help is sought from sources outside the public health system. Understanding the helpseeking pattern for mental health problems among immigrant populations is important if research, policy, and tailored health program initiatives are to reach vulnerable or isolated groups. Our focus in this paper is on help-seeking for depression because of its high prevalence, and comorbidity with other common diseases [14].

Although there are many definitions of help-seeking [15], it is defined here as a request for assistance from formalized services or for informal support for the purpose of resolving emotional, behavioral, or health problems [16]. From a public health perspective, the proposed Behavioral Model of Health Service Use [17] is useful for understanding ethnic differences in helpseeking preferences $[17,18]$. According to this model $[17,18]$, three interrelated groups of factors influence all health behavior, including help-seeking behavior: predisposing factors (e.g., gender, ethnicity, and socioeconomic status); need factors (e.g., self-perceived need and professional evaluation), and enabling factors (e.g., ability to pay for healthcare, health literacy, and social support). The model suggests that health behaviors are continuously re-defined by experience and that they influence all health outcomes. Based on a systematic review, Malgaard and colleagues [19] concluded that belonging to certain ethnic minority groups represented a risk of not seeking professional help for depression (based on U.S. and Canadian data sets). For example, African Americans and Mexican Americans had lower rates of seeking help for major depression compared to those with a Caucasian background. Differences were attributed to mental health literacy and attitude-related barriers such as shame [5]. With a view to improving ethnic minority patients' access to care, three recent review papers on mental help-seeking behavior $[5,19,20]$ highlight that further research should explore beliefs about what constitute appropriate sources of care and help-seeking for mental health concerns in specific ethnic and religious minorities groups.

It is a widely held assumption that the more immigrants integrate into the dominant culture of their country of settlement, the more they will adopt the health patterns of the majority [21]. In line with this, we expect acculturation to be an important variable in terms of understanding individual variations in help-seeking within immigrant groups. Acculturation is defined as the changes in values and behaviors individuals make to accommodate to the culture of settlement [22]. Berry [22] argued that acculturation addresses two underlying dimensions: the degree to which one's heritage culture is maintained and the degree to which one wishes to participate and have contact with other cultural groups. This two-dimensional perspective implies that immigrants can maintain or neglect their home culture, while simultaneously adopting or not adopting the culture of settlement [22]. Thus, immigrants may retain traditional help-seeking patterns from their home culture despite long residence time and adoption of the majority culture in other domains. In line with previous research [21, 23], there is reason to assume that immigrants who adopt the majority culture are likely to be more positive about seeking help from public health services (formal sources) than immigrants who do not. However, studies on acculturation orientation and help-seeking are few and divergent, and they have mainly concerned Asian-American immigrant groups in the US [23]. More research has been called for on specific migrant groups and how they view mental illness [24]. Because immigrant groups differ significantly between and within themselves as regards enabling, predisposing, and need factors, differences within immigrant groups are as interesting as differences between immigrant groups and the native Norwegian population. Previous research has shown that several factors can influence acculturation orientation, most importantly gender, and length of time abroad [23].

Against this backdrop, this study aims to examine and compare preferred help-seeking sources for depression among different immigrant groups (Poles, Russians, Somalis, and Pakistanis) in Norway and how such 
preferences relate to acculturation orientation. The immigrant groups were chosen because they are among the largest immigrant groups in Norway [8]. At the group level, they also differ in terms of years lived in Norway, the reason for migration, and religious orientation. In this paper, the term "immigrants" is defined as persons who have either immigrated to Norway themselves or were born of two non-Norwegian-born parents. We focus on lay people instead of a clinical population. Lay people refer to persons who are not mental healthcare professionals. The high prevalence of depression suggests that many people will experience this disease either themselves or their family members will. Research suggests that, particularly in communal cultures, the views of family members will strongly influence the choice of help-seeking sources [25]. Thus, the understandings of lay people may be highly informative about how immigrants experience and cope with depression.

Recruiting a representative sample of migrants to surveys is challenging. In the present study digital social platforms (Facebook, LinkedIn), emails, and direct contact were used to target and recruit participants. This approach was combined with snowball sampling, that is, immigrants interested in participating in the study were asked to encourage the participation of immigrants from the same country of origin. Although this flexible approach resulted in a convenience sample, it was preferred to more traditional techniques such as population register-based sampling and onomastic (name-based) sampling [26-28]. Registers are often incomplete when it comes to foreign citizenship, and linguistic screening of names have obvious shortcomings as they frequently cannot identify ethnic group membership with certainty. Vulnerable immigrant groups may be reluctant to participate in surveys for several reasons ranging from the experience of persecution and mistrust of authorities in their countries of origin to cultural issues and language skills. The choice of recruitment method in the present study was based on an assumption that immigrants would be more willing to participate if members of their ethnic group encouraged participation.

\section{Methods}

\section{Sample and study participants}

A convenience sample of 533 respondents was recruited from four immigrant groups in Norway. In addition, data from Norwegian students $(N=250)$ were used as a native comparison in parts of the analyses. In total, 81 respondents had more than 30 missing data points (out of 783 responses; $10 \%$ ) and were excluded from all statistical analyses. Hence, the final sample consisted of 702 participants. The age of the respondents ranged from 19 to 64 years with a mean of $30.8(S D=9.3)$. Power analysis was conducted with G*Power, version 3.0.3 [29].
Setting alpha to .05 (two-tailed), power (1- $\beta$ ) to .80 , and effect sizes (Cohens $d$ ) to 0.2 (small), 0.5 (medium), and 0.8 (large) comparing five groups shows that a total of 1200 , 200 and 80 respondents were needed, respectively. As we recruited about 100 subjects from each group, we were accordingly able to detect medium and larger effect sizes.

\section{Procedure Immigrant samples}

The survey was distributed and collected on paper $(n=$ $33)$ or online $(n=500)$. The possibility of answering the survey on paper was only offered to the Somali respondents. Some of the data on Somali immigrants have been presented in a previous paper [30]. As for the online survey, the respondents were recruited through social network sites (e.g., Facebook, online immigrant organizations). Only those who actively expressed consent received the online link or the paper version of the survey. Prior to answering the questionnaires, respondents were informed that the study aimed to provide more knowledge about how people from different cultures think that one should best deal with feelings such as sadness and that such knowledge could inform the development of health services adapted to the needs of minority groups. Respondents were also informed about how data would be handled in all phases of data collection and publication. Data were collected by the first author and four researcher-assistants with origin in Russia, Poland, Somalia, and Pakistan. Respondents with Somali and Pakistani origin could choose to answer the survey in either Arabic, English, or Norwegian. Respondents with Russian and Polish origin could in addition, choose to answer the survey in Russian and Polish, respectively. The instruments were translated using a translation-back-translation procedure, comparing versions to maximize technical, semantic, content, and conceptual equivalence.

\section{The Norwegian sample}

The survey was distributed online. A research assistant invited respondents via a private message on Facebook or by email. The students were mainly recruited from higher education institutions in Norway. Except for psychology students who were not recruited due to their professional training background in mental health care, students were invited to participate in the study independent of their academic discipline. The student sample represented different academic disciplines: 30\% humanities (e.g., pedagogy), 30\% social sciences (e.g., psychology), $11 \%$ natural sciences (e.g., chemistry), 16\% medicine (e.g., nursing) and 13\% from formal science disciplines and professions (e.g., law and real estate management). Students $(n=25)$ who had migrated from other countries were not included in the analysis. 


\section{Instruments}

The first part of the survey consisted of questions about demographics, including age, gender, ethnicity, years of formal education, and length of residence in Norway. Respondents were then asked to read a vignette (Table 1), describing a person with symptoms of depression consistent with the criteria for a depressive episode in the International Classification of Diseases-10 [31]. The gender of the vignette character was matched to the respondent to facilitate identification.

After reading the vignette, the respondents answered questionnaires about help-seeking preferences and acculturation orientation.

The General Help-Seeking Questionnaire [30, 32] (GHSQ) consists of 19 items describing different sources from whom help can be sought (e.g., friends, traditional healer, and telephone helpline). Each item was rated on a six-point Likert scale ( 1 = "very unlikely" to $6=$ "very likely"). The standard instruction: "If you were having [problem-type], how likely is it that you would seek help from the following people?" [32], was modified to: "If you were feeling like Ann/John (gender-matched), how likely is it that you would seek help from the following sources?". In line with the recommendations of Wilson et al. [32], relevant items were added to fit the target group. Specifically, we included items referring to helpseeking sources in the immigrant community (e.g., traditional healers, elders in my community, leaders in my ethnic community or from the same country as me, other people in my ethnic community or from the same country as me) and alternative medicine (e.g., acupuncture, homeopathy). One source (the Norwegian Labor and Welfare Administration, abbreviated to Social Worker/NAV in the survey) was added to adapt the questionnaire to the Norwegian context.

Table 1 Vignette used in the survey

"John/Ann is a 27-year-old waiter in a restaurant in Bergen. He/she was born in Oslo to parents who were restaurant owners, but has made Bergen his/her home for 5 years. In the last few weeks, he/she has been experiencing feelings of sadness every day. John/Ann's sadness has been continuous, and he/she cannot attribute it to any specific event or to the season of the year. It is hard for him/her to go to work every day; he/she used to enjoy the company of his/her co-workers and working at the restaurant, but now he/she cannot find any pleasure in this. In fact, John/Ann has little interest in most activities that he/she once enjoyed. He/she is not married and lives alone, near his/her brother/sister. Usually, they enjoy going out together and with friends. But now he/she does not enjoy this anymore. John/Ann feels very guilty about feeling so sad, and feels that he/she has let down his/her brother/sister and friends. He/she has tried to change his/ her work habits and start new hobbies to become motivated again, but he/she cannot concentrate on these tasks. Even his/her brother/sister has now commented that John/Ann gets distracted too easily and cannot make decisions. Since these problems began, John/Ann has been sleeping poorly every night; he/she has trouble falling asleep and often wakes up during the night. A few nights ago, as he/she lay awake, trying to fall asleep, John/Ann began to cry because he/she felt so helpless."

In the Russian version, the male name John was changed to the more typical Russian name Zenia
The Vancouver Index of Acculturation [33] (VIA) measures acculturation orientation. It consists of 20 statements assessing interest and participation in one's heritage culture (10 items) and the mainstream (Norwegian) culture in the country of residence (10 items). Each item was rated on a nine-point Likert scale $(1=$ "strongly disagree" to $9=$ "strongly agree"). The average of the 10 items in each subscale was computed, resulting in a score for each participant on the heritage subscale and on the mainstream subscale. These scales are in the following referred to as "Maintenance" and "Adoption".

\section{Data analysis}

SPSS 24.0 was used for all statistical analyses. A parallel principal component analysis (with Varimax rotation) of all items in the GHSQ was conducted of help-seeking sources that tend to be used simultaneously. Items with cross-loadings of .40 or higher on two or more factors were removed [34]. Based on the results, composite scores for the subscales were computed for each factor. Secondly, differences in means between all immigrant groups were assessed using a multivariate analysis of variance (MANOVA) and Tukey post-hoc tests. Thirdly, a correlation analysis was conducted to explore the relationship between preferred help-seeking sources, acculturation orientation (only immigrants), and background variables. Finally, a hierarchical multiple regression analysis was conducted to investigate whether the acculturation subscales explained help-seeking preferences when controlling for gender, age, years of higher education and ethnicity in the immigrant sample. Age was controlled for by partial correlation analysis and an analysis of covariance (ANCOVA), and no significant differences were observed (results not shown).

\section{Results}

\section{Descriptive statistics}

Table 2 shows the demographic characteristics of the different subsamples.

\section{Factor structure of the GHSQ}

A principal component analysis (Table 3) yielded four factors with eigenvalues exceeding 1, accounting for $57 \%$ of the total variance. A scree plot and parallel analysis both supported the 4-factor solution. Two items were deleted due to cross-loadings ("I would not seek help from anyone" and "I would seek help from my manager or human resource staff at my workplace"), and one item ("I would seek help from social worker/NAV") was deleted because the content diverged from the other items with high loading on the factor. Fifteen items were included in further analyses. Bartlett's test of sphericity was significant, and the Kaiser-Mayer-Olkin measure of sampling was acceptable $(\leq .81)$. The first factor, 
Table 2 Descriptive statistics for the samples

\begin{tabular}{|c|c|c|c|c|c|}
\hline Country of origin & Norway $(n=225)$ & Russia $(n=151)$ & Poland $(n=109)$ & Pakistan $(n=117)$ & Somalia $(n=100)$ \\
\hline & $M(S D)$ & $M(S D)$ & $M(S D)$ & $M(S D)$ & $M(S D)$ \\
\hline Age & $27.3(7.0)$ & $34,8(8.5)$ & $34.4(9.6)$ & $28.5(10.2)$ & $28.9(8.3)$ \\
\hline Years in Norway & Not relevant & $7.9(5.2)$ & $6.1(5.8)$ & $16.7(8.8)$ & $9.3(7.1)$ \\
\hline Born in Norway ( $N$ ) & Not relevant & 11 & 2 & 86 & 0 \\
\hline Higher education ${ }^{\mathrm{a}}$ & $100 \%$ & $79 \%$ & $79 \%$ & $80 \%$ & $35 \%$ \\
\hline Females & $69 \%$ & $87 \%$ & $77 \%$ & $69 \%$ & $44 \%$ \\
\hline
\end{tabular}

${ }^{a}$ Includes those who have started, are undertaking or have completed studies at the university level

explaining $26 \%$ of the variance, covered help-seeking from religious leaders, healers, elders, and members of the ethnic community. This factor was labelled traditional. The second factor, explaining $13 \%$ of the variance, included family members, friends, and partners. This factor was labelled informal. The third factor, explaining $10 \%$ of the variance, concerned phone helplines, internet forums, and a work colleague, and was labelled semiformal. The fourth factor, explaining $8 \%$ of the variance, comprised general practitioners and psychiatrists/psychologists and was labelled formal. The same analysis of only the immigrant sample resulted in a similar factor structure.

\section{Differences across ethnic groups in health-seeking sources}

The results from the MANOVA with Tukey's post-hoc tests, with factor scores as dependent variables and ethnic group affiliation as an independent variable, are presented in Table 4. Preliminary assumption testing was conducted to check for normality, linearity, univariate and multivariate outliers, and multicollinearity, with no serious violations being noted. Levene's test showed, however, that the assumption of equality was violated. In line with the recommendations of Tabachnick and Fidell [35], a more conservative alpha (.025) level was therefore used. Three of the help-seeking factors varied significantly between ethnic groups: traditional help-seeking $\left(F_{4,697}=65.18, p<0.001\right)$, informal help-seeking $\left(F_{4,697}=7.66, p<0.001\right)$, and formal helpseeking $\left(F_{4,697}=3.20, p<0.025\right)$. Specifically, the Somali respondents showed a stronger preference for traditional help-seeking than respondents from the other ethnic groups. Post-hoc tests indicated that the mean score for the Traditional factor for respondents of Somali origin was significantly different from the Pakistani immigrant sample, with a moderate effect size $(d=0.64)$, and the Russian immigrant sample $(d=0.99)$, Polish immigrant sample $(d=1.24)$, and Norwegian student sample $(d=$ 1.32), with large effect sizes. The mean score of the Pakistani immigrant sample on the Traditional factor

Table 3 Factor loadings for parallel principal component analysis with varimax rotation of help-seeking questionnaire

\begin{tabular}{|c|c|c|c|c|}
\hline & Traditional & Informal & Semiformal & Formal \\
\hline Leader in my ethnic community or from the same country as me & .84 & .09 & .20 & -.04 \\
\hline Elders in my community & .80 & .15 & .12 & -.01 \\
\hline Traditional healer & .76 & -.00 & .14 & .08 \\
\hline Other people in my ethnic community or from the same country as me & .75 & .13 & .18 & -.08 \\
\hline Religious leader (e.g., priest, rabbi, chaplain, mullah) & .72 & .15 & .04 & -.02 \\
\hline Alternative medicine (e.g., acupuncturist, homeopath) & .60 & -.04 & .08 & .26 \\
\hline Parents & .18 & .75 & -.04 & .01 \\
\hline Friends & .04 & .74 & .14 & .05 \\
\hline Intimate Partner (e.g., girlfriend, boyfriend, husband, wife) & -.13 & .72 & -.01 & .15 \\
\hline Other relative/Family member & 32 & .61 & .09 & .05 \\
\hline Telephone helplines & .24 & -.03 & .75 & .20 \\
\hline Internet forums & .03 & -.03 & .79 & .09 \\
\hline Work colleague & .28 & .36 & .56 & -.02 \\
\hline Psychiatrist/psychologist & -.01 & .04 & .10 & .85 \\
\hline Medical doctor/GP & .11 & .19 & .13 & .78 \\
\hline
\end{tabular}

Items loaded under the same factor in boldface 
Table 4 MANOVA Differences in help-seeking strategies based on ethnic groups (factor level)

\begin{tabular}{|c|c|c|c|c|c|c|c|c|}
\hline Country of origin & Norway & Russia & Poland & Pakistan & Somalia & $F(4,729)$ & $p$ & Partial Eta Square \\
\hline & $M(S D)$ & $M(S D)$ & $M(S D)$ & $M(S D)$ & $M(S D)$ & & & \\
\hline Traditional & $1.39(0.64)^{a}$ & $1.78(0.73)^{b, c}$ & $1.51(0.73)^{a, b}$ & $2.09(0.94)^{c}$ & $2.57(1.26)^{d}$ & 65.17 & $<0.00$ & 0.24 \\
\hline Informal & $3.80(1.12)^{\mathrm{a}}$ & $4.03(0.97)^{\mathrm{a}}$ & $3.78(1.14)^{\mathrm{a}}$ & $4.04(1.17)^{\mathrm{a}}$ & $4.50(1.13)^{b}$ & 7.65 & $<0.00$ & 0.04 \\
\hline Semiformal & $2.24(0.87)^{a, b}$ & $2.31(0.95)^{a, b}$ & $2.15(1.07)^{\mathrm{a}}$ & $2.17(0.98)^{a, b}$ & $2.34(1.14)^{b}$ & 2.55 & 0.04 & 0.01 \\
\hline Formal & $3.62(1.33)^{a}$ & $3.31(1.36)^{\mathrm{a}}$ & $3.37(1.51)^{\mathrm{a}}$ & $3.22(1.30)^{\mathrm{a}}$ & $3.35(1.44)^{a}$ & 3.02 & 0.01 & 0.02 \\
\hline
\end{tabular}

Means within a row with different subscripts are significantly different at $p \leq .025$

was significantly different from the Russian immigrant sample $(d=1.22)$ and Norwegian student sample $(d=$ $0.87)$, with large effect size, and from the Polish immigrant sample $(d=0.69)$, with a moderate effect size. The Russian immigrant sample was significantly different from the Norwegian student sample, with a moderate effect size $(d=0.57)$. All immigrant samples and the Norwegian students scored highest on the Informal factor relative to the three other factors. Respondents of Somali origin scored higher on the Informal help-seeking factor than the Pakistani $(d=0.40)$, Russian $(d=0.43)$, and Polish immigrant samples $(d=0.62)$ and the Norwegian student sample $(d=0.61)$, with moderate effect sizes. Scores on Formal help-seeking also varied significantly between ethnic groups, but post-hoc tests show no significant results.

\section{Help-seeking factors in relation to acculturation orientation and demographic variables}

The correlational analysis (Table 5) showed that endorsement of traditional and informal help-seeking sources was positively associated with a maintenance acculturation orientation, while endorsements of semiformal and formal help-seeking sources were positively associated with an adoption acculturation orientation. This indicates that acculturation orientation may influence help-seeking preferences. Higher education correlated negatively with the endorsement of traditional help-seeking sources and positively with adoption acculturation orientation and age. There were also significant gender differences. Men endorsed traditional helpseeking sources more than women, whereas women endorsed formal help-seeking sources more often than men.

Finally, a hierarchical multiple regression analysis was carried out (see Table 6). Since different approaches to help-seeking are associated with age, gender, education level, and ethnicity $[17,19,23]$ we controlled for these factors in the regression analysis when investigating the impact of acculturation orientation on types of helpseeking behavior. Demographic variables were entered in the first block, followed by the acculturation orientation factors of maintenance and adoption, which were entered in the second block. Russian immigrant sample

Table 5 Mean, standard deviations, and correlations between help-seeking strategies, acculturation orientation and demographic characteristics

\begin{tabular}{|c|c|c|c|c|c|c|c|c|c|c|}
\hline & $M$ & $S D$ & 1 & 2 & 3 & 4 & 5 & 6 & 7 & 8 \\
\hline \multicolumn{11}{|l|}{ Help-seeking } \\
\hline 1.Traditional & 1.80 & 0.96 & .84 & & & & & & & \\
\hline 2. Informal & 4.00 & 1.10 & $.26^{* *}$ & .71 & & & & & & \\
\hline 3.Semiformal & 2.30 & 1.01 & $.31^{* *}$ & $.20^{* *}$ & .60 & & & & & \\
\hline 4. Formal & 3.46 & 1.40 & $.08^{*}$ & $.14^{* *}$ & $.22^{* *}$ & .61 & & & & \\
\hline \multicolumn{11}{|l|}{ Acculturation $^{a}$} \\
\hline 5. Maintenance & 6.57 & 1.70 & $.27^{* *}$ & $.31^{* *}$ & .06 & .05 & .90 & & & \\
\hline 6. Adoption & 5.60 & 1.70 & -.06 & .05 & $.16^{* *}$ & $.14^{* *}$ & $.19^{* *}$ & .90 & & \\
\hline \multicolumn{11}{|l|}{ Demographic } \\
\hline 7. Gender ${ }^{b}$ & 30.80 & 9.30 & $-.09^{*}$ & .03 & -.01 & $.14^{* *}$ & .02 & .05 & & \\
\hline 8. Age & 2.77 & 1.30 & .06 & $-.10^{* *}$ & -.00 & .02 & -.03 & -.07 & .05 & \\
\hline 9. Higher education & 1.70 & 0.46 & $-.18^{* *}$ & -.00 & .01 & -.04 & -.05 & $.22^{* *}$ & .07 & $.24^{* *}$ \\
\hline
\end{tabular}

Note. The coefficients on the diagonal in bold are the Cronbach's alpha of each scale ${ }^{\mathrm{a}}$ Only immigrant sample $(n=452) .{ }^{\mathrm{b}} 1=$ male, $2=$ female

${ }^{*} p \leq .05,{ }^{* *} p \leq 0.01$ (2-tailed) 
Table 6 Summary of results from hierarchical multiple regression analyses ( $N=452)$

\begin{tabular}{|c|c|c|c|c|c|c|c|c|}
\hline & \multicolumn{4}{|c|}{ Traditional } & \multicolumn{4}{|c|}{ Informal } \\
\hline & $b$ & $\beta$ & $95 \% \mathrm{Cl}$ & $p$ & $b$ & $\beta$ & $95 \% \mathrm{Cl}$ & $p$ \\
\hline \multicolumn{9}{|l|}{ Step 1} \\
\hline Gender $^{a}$ & -.12 & -.06 & $-.32, .08$ & .225 & .18 & .07 & $-.06, .43$ & .147 \\
\hline Age & .10 & .10 & $.00, .02$ & .029 & -.01 & -.06 & $-.02, .00$ & .212 \\
\hline Education $^{b}$ & -.15 & -.19 & $-.22,-.07$ & $<.000$ & .01 & -.08 & $-.11, .09$ & .890 \\
\hline Somalia & .69 & .28 & $.40, .99$ & $<.000$ & .44 & .15 & $.06, .81$ & .022 \\
\hline Pakistan & .22 & .10 & $-.02, .47$ & .076 & .00 & .00 & $-.31, .31$ & .989 \\
\hline Poland & -.37 & -.16 & $-.61,-.13$ & .002 & -.27 & -.10 & $-.57, .04$ & .095 \\
\hline$R^{2}$ & & .22 & & $<.000$ & & 05 & & .001 \\
\hline \multicolumn{9}{|l|}{ Step 2} \\
\hline Gender & -.15 & -.07 & $-.34, .05$ & .138 & .15 & .06 & $-.09, .39$ & .215 \\
\hline Age & .01 & .01 & $.00, .02$ & .034 & -.01 & -.07 & $-.02, .00$ & .183 \\
\hline Education & -.14 & -.18 & $-.22,-.06$ & $<.000$ & -.01 & -.01 & $-.10, .09$ & .901 \\
\hline Somalia & .61 & .25 & $.32, .91$ & $<.000$ & .34 & .12 & $-.03, .70$ & .070 \\
\hline Pakistan & .21 & .09 & $-.03, .45$ & .083 & -.01 & -.00 & $-.31, .29$ & .940 \\
\hline Poland & -.34 & -.14 & $-.57,-.10$ & .005 & -.19 & -.07 & $-.49, .10$ & .201 \\
\hline Maintenance & .13 & .03 & $.08, .18$ & $<.000$ & .19 & .28 & $.13, .26$ & $<.000$ \\
\hline Adoption & -.02 & .03 & $-.07, .03$ & .478 & -.00 & -.00 & $-.07, .06$ & .986 \\
\hline$\Delta R^{2}$ & & .04 & & $<.000$ & & .08 & & $<.000$ \\
\hline \multirow[t]{3}{*}{ Total $R^{2}$} & & .28 & & $<.000$ & & .13 & & $<.000$ \\
\hline & \multicolumn{4}{|c|}{ Semiformal } & \multicolumn{4}{|c|}{ Formal } \\
\hline & $b$ & $\beta$ & $95 \% \mathrm{Cl}$ & $p$ & $b$ & $\beta$ & $95 \% \mathrm{Cl}$ & $p$ \\
\hline \multicolumn{9}{|l|}{ Step 1} \\
\hline Gender $^{\mathrm{a}}$ & .03 & .01 & $-.20, .28$ & .788 & .61 & .20 & $.31, .91$ & $<.000$ \\
\hline Age & -.00 & -.03 & $-.02, .01$ & .524 & .01 & .08 & $-.00, .03$ & .128 \\
\hline Education $^{\mathrm{b}}$ & -.01 & -.02 & $-.11, .08$ & .787 & .01 & .01 & $-.11, .12$ & .917 \\
\hline Somalia & -.01 & -.01 & $-.38, .35$ & .943 & .38 & .11 & $-.07, .83$ & .099 \\
\hline Pakistan & -.14 & -.06 & $-.44, .16$ & .363 & .20 & .06 & $-.17, .58$ & .283 \\
\hline Poland & -.15 & -.06 & $-.44, .15$ & .331 & .30 & .09 & $-.07, .66$ & .110 \\
\hline$R^{2}$ & & .01 & & .889 & & .04 & & .003 \\
\hline \multicolumn{9}{|l|}{ Step 2} \\
\hline Gender & .04 & .02 & $-.20, .28$ & .737 & .62 & .20 & $.33, .92$ & $<.000$ \\
\hline Age & -.00 & -.02 & $-.01, .01$ & .768 & .01 & .10 & $.00, .03$ & .054 \\
\hline Education & -.04 & -.05 & $-.13, .06$ & .437 & -.03 & -.03 & $-.14, .01$ & .647 \\
\hline Somalia & .07 & .02 & $-.30, .43$ & .727 & .49 & .14 & $.04, .93$ & .056 \\
\hline Pakistan & -.13 & -.05 & $-.43, .17$ & .387 & .22 & .07 & $-.15, .58$ & .247 \\
\hline Poland & -.05 & -.02 & $-.35, .24$ & .733 & .42 & .13 & $.06, . .78$ & .063 \\
\hline Maintenance & .01 & .02 & $-.05, .08$ & .675 & .01 & .01 & $-.07, .09$ & .767 \\
\hline Adoption & .12 & .18 & $.05, .18$ & $<.000$ & .16 & .19 & $.08, .24$ & $<.000$ \\
\hline$\Delta R^{2}$ & & .03 & & .001 & & .063 & & $<.000$ \\
\hline Total $R^{2}$ & & .04 & & .001 & & .08 & & $<.000$ \\
\hline
\end{tabular}

${ }^{\mathrm{a}} 1=$ male, 2 = female; ${ }^{\mathrm{b}} 1$ = no higher education, $5=$ Ph.D. level 
was used as the contrast/reference group in the regression analyses. Missing data were dealt with by pairwise deletion. Gender accounted for a significant variance. Female respondents endorsed formal help-seeking sources more than men. The results also show that the Somali respondents preferred traditional and informal help-seeking sources more than the contrast/reference group. The Polish respondents preferred traditional help-seeking sources to a smaller degree than the contrast/reference group.

\section{Discussion}

The overall aim of this study was to examine and compare preferred help-seeking sources for depression among different immigrant groups (Poles, Russians, Somalis, and Pakistanis) in Norway, and to provide more insight into how such preferences relate to individual differences in acculturation orientation. Factor analysis suggested four main categories of help-seeking sources, labelled traditional, informal, semiformal, and formal. A similar classification into informal, semiformal, and formal help-seeking sources was suggested by Rickwood and Thomas [15] following a systematic review. They noted that classifications are not absolute, since different countries have different health and social care systems. For example, traditional healers could be a critical source of formal health care in a traditional indigenous population group. In the present study, traditional sources emerged as one distinct factor, comprising helpseeking from religious leaders, alternative medicine providers, and ethnic community members. It is also possible that the emergence of the semiformal helpseeking factor (that included internet forums), was influenced by the fact that the majority of participants being recruited from social media and therefore likely to be familiar with using digital platforms.

The results indicate that independent of ethnicity, respondents preferred to rely on informal sources of help, such as friends and family, before turning to semiformal (e.g., telephone helplines) or formal (psychologists/psychiatrists and general practitioners) help sources. This is in line with previous research [36, 37] highlighting the importance of social networks in coping with mental health problems. Surprisingly, and contrary to previous studies $[11,38,39]$, there were no differences between ethnic groups in preferences for formal helpseeking sources. This is an important finding since earlier research has indicated that some ethnic groups may have a lower preference for formal sources of help due to lower mental health literacy [40]. Our findings indicate that all groups recognize formal sources of help as valuable. One possible explanation for these different findings is that all legal residents in Norway have access to public health care and that costs are low. All citizens are entitled to a general practitioner. Once a person reaches an annual limit (currently about NOK 2000), services are free. However, when interpreting the findings, it should be kept in mind that some immigrants, in particular from countries where mental health services are sparse or non-existent, may not have a clear understanding of what a psychologist is or the nature of psychological treatment. Moreover, one should be mindful that the formal help factor only consisted of two items, which may explain why the internal consistency was rather low. We cannot rule out that the introduction provided to the respondents when they were invited to participate could have made them more inclined to endorsing formal help sources as they were informed that the study concerned how "one could best deal with feelings such as sadness" and that "the results could inform the development of health services adapted to the needs of minority groups". According to Wright, Jorm, and Mackinnon [41] labelling a disorder has implications for helpseeking preferences and beliefs. However, the term depression was deliberately not used in the information provided to the participants. Therefore, we overall regard it unlikely that the instructions impacted substantially on the results.

Immigrants and refugees from Somalia and Pakistan endorsed more traditional and informal sources of help than immigrants from countries culturally closer to Norway (Russia and Poland) and the Norwegian sample. Thus, as the cultural distance grows, the conceptualization of what constitutes effective help-seeking sources seems to diverge. If informal and traditional sources are influential in determining treatment choices in depressed friends and family, this may highlight their potential role as gatekeepers or gate-openers for public mental health services [36]. The Norwegian student sample scored significantly lower than most ethnic groups on preference for traditional sources of help. This is consistent with previous research [42]. However, the lower endorsement of helpseeking from traditional sources may be due to the possible perceived irrelevance to the Norwegian respondents of some of the questions loading on the traditional factor (e.g., "seeking help from a leader in my ethnic community or from the same country as me").

The results of the hierarchical regression analysis showed that acculturation orientation explained only a modest portion of the variance in preferred help-seeking sources. However, the pattern of correlations was in accordance with previous findings $[38,43]$. Orientation towards heritage culture was associated with a preference for traditional and informal sources of help, while orientation towards mainstream (Norwegian) culture was associated with endorsement of semiformal and formal sources of help. 
The current findings suggest that demographic variables should also be taken into consideration when designing interventions for immigrants. Women took a more positive view of formal help-seeking sources, while males took a more positive view of traditional help-seeking sources [19]. There may be several explanations for these findings, for example, the stigma attached to mental health among male respondents that have been reported in previous findings [20,44]. Years of higher education was positively associated with endorsement of formal sources and negatively associated with endorsement of traditional helpseeking sources. These findings suggest that immigrants with lower education are more likely to seek help from sources outside the existing health services. This may give cause for concern because lower education, often associated with lower socio-economic status, is a risk factor for poorer mental health.

\section{Methodological considerations}

Our results should be interpreted in light of certain limitations. The use of a vignette is useful in studies of nonclinical populations to attempt to determine what people who are not experiencing symptoms would do if they were to experience symptoms [15]. This approach may also have reduced the impact of social desirability since the respondents were not asked to report their mental health behavior. It can still be questioned whether the response to the question of what a hypothetical person should do reflects how the respondents themselves would have acted if they or someone in their family were depressed. Issues related to the representativeness of the samples need to be kept in mind. Participants in the present study were recruited through convenience sampling, primarily via emails, social media, and through snowball sampling. The latter sampling method is recommended when working with hardto-reach population groups, such as ethnic minorities [26, 27]. In terms of recruitment through social media, it has been noted that this may lead to a mismatch between the target population and those recruited, especially regarding demographic variables [45]. The use of social media for recruitment may thus explain the preponderance of young participants. Taken together, lack of familiarity with social media platforms, low reading literacy, lack of acquaintance with questionnaires, and access to the internet are factors likely to have prevented participation in the study.

Readers should be mindful that these and other factors may influence the comparability of the samples. Ethnic differences in response styles [46] represent a possible bias, but we believe that the influence of this possible bias was minor as there was no evidence suggesting that specific ethnic groups consistently scored higher or lower on the scales. Educational attainment varied much between the groups. For the Pakistani, Polish and Somali samples, the portion with higher education are close to being representative for these immigrant groups in Norway, but in the Russian sample, a larger portion had higher education compared to the Russian immigrant population in Norway [47]. Also, the Norwegian students were on average somewhat younger and had a higher education level than the other groups. Except for the Somali immigrants, females were in the majority. To control for the possibility that gender, age, or level of education or interactions between these variables are responsible for the differences between the ethnic groups observed, we adjusted for these variables in the regression analyses. We acknowledge that it may be problematic to generalize from students to the general public [48]. Nonetheless, in Norway, the population's education level is high, particularly in the younger age groups. Among those aged 15-64 years in 2019, 38\% have a university or college degree compared to $28 \%$ in the European Union [49]. As a general rule, higher education is free of charge and Norwegian students are entitled to loans and grants from the State Educational Loan Fund. Therefore, the student population in Norway is probably more heterogeneous regarding backgrounds than in many other countries [50]. Recent research on Norwegian students enrolled in higher education showed higher levels of mental health problems than the general population [51]. The high prevalence of mental health problems in university students correspond with data from other countries [52], indicating that this group may be particularly relevant when examining help-seeking behavior for mental health problems.

\section{Conclusion}

Future studies are needed to understand the mechanisms underlying ethnic differences in help source preferences, as well as to enable the generalization of the results from this study to more heterogeneous populations. Nonetheless, the results from this study suggest that immigrants' preferred help-seeking sources differ by ethnic group, gender, level of education, and acculturation orientation. The differences were particularly evident as regards choosing traditional help-seeking sources. One implication of the findings is that public health services for ethnic minority patients, in particular for men and those with lower education, should consider integrating formal, informal, and traditional help sources, such as ethnic community members, religious leaders, and family networks when designing and implementing mental health services.

\section{Abbreviations \\ VIA: The Vancouver Index of Acculturation; GHSQ: The General Help-Seeking Questionnaire}

\section{Acknowledgements}

The authors wish to thank Ilham Hassan, Abdulqadar Hussein, Aurelian

Savoye, and Sara Sabir for the help with the data collection. The authors are 
also grateful to all the participants who took their time to answer in the survey.

\section{Consent to participate}

Not applicable.

\section{Authors' contributions}

VM led the conception and design of the study, analysis, interpretation of the data, drafting, writing, and revising the work. All authors (VM, GM, SP) contributed to the design, analysis, and interpretation of the data, and/or writing and revising the work critically for important intellectual content. Al authors read and approved the final version of the work to be published (VM, GM, SP).

\section{Funding}

The study was funded by the Western Norway Regional Health Authority (project number 911834) and the Norwegian Research Council (project number 273645). Project number 911834 has covered the PhD grant for one of the authors, and Project number 273645 covered payroll expenses.

\section{Availability of data and materials}

The datasets used for the current study are available from the corresponding author upon request.

\section{Ethics approval and consent to participate}

The study was approved by the Regional Committee for Medical and Health Research Ethics (2013/2181) and the Norwegian Social Science Data Services. The anonymity of the respondents was ensured as they were not asked to provide any personal information that could identify them Respondents provided their consent by pressing the "next" button in the online version or signed a declaration of consent (for those who completed the survey on paper).

\section{Competing interests}

The authors declare that they have no conflicts of interest.

\section{Author details}

${ }^{1}$ Department of Pulmonology, Haukeland University Hospital, Bergen, Norway. ${ }^{2}$ Department of Psychosocial Science, University of Bergen, Bergen, Norway. ${ }^{3}$ Optentia Research Focus Area, North-West University,

Vanderbijlpark Campus, Vanderbijlpark, South Africa.

\section{Received: 29 August 2019 Accepted: 28 June 2020}

\section{Published online: 11 July 2020}

\section{References}

1. Lindert J, von Ehrenstein OS, Priebe S, Mielck A, Brähler E. Depression and anxiety in labor migrants and refugees - a systematic review and metaanalysis. Soc Sci Med. 2009;69(2):246-57.

2. Abebe DS, Lien L, Hjelde KH. What we know and don't know about mental health problems among immigrants in Norway. J Immigr Minor Health. 2014;16:60-7.

3. Kirmayer LJ, Narasiah L, Munoz M, Rashid M, Ryder AG, Guzder J, et al. Common mental health problems in immigrants and refugees: general approach in primary care. Can Guidlines Immigr Health. 2011;183(12): 959-67.

4. Dalgard OS, Thapa SB, Hauff E, McCubbin M, Syed HR. Immigration, lack of control and psychological distress: findings from the Oslo health study. Scand J Psychol. 2006:47(6):551-8.

5. Kale E, Hjelde KH. Mental health challenges of immigrants in Norway: Norwegian Centre for Migration and Minority Health (NAKMI); 2017. Available from: http://www.nakmi.no/publikasjoner/dokumenter/mentalhealth-challenges-of-immigrants-in-norway-NAKMI-rapport-1-2017.pdf.

6. Straiton ML, Reneflot A, Diaz E. Mental health of refugees and non-refugees from war-conflict countries: data from primary health services and the Norwegian prescription database. J Immigr Minor Health. 2017;19(3):582-9.

7. Diaz E, Gimeno-Feliu L-A, Calderón-Larrañaga A, Prados-Torres A. Frequent attenders in general practice and immigrant status in Norway: a nationwide cross-sectional study. Scand J Prim Health Care. 2014;32(4):232-40.

8. Abebe DS, Lien L, Elstad Jl. Immigrants' utilization of specialist mental healthcare according to age, country of origin, and migration history: a nation-wide register study in Norway. Soc Psychiatry Psychiatr Epidemiol. 2017;52(6):679-87.

9. Elstad J, Finnvold JE, Texmon I. Bruk av sykehus og spesialisthelsetjenester blant innbyggere med norsk og utlandsk bakgrunn [Use of hospital and specialist health among residents with Norwegian and foreign backgrounds]: Norwegian Social Research (NOVA); 2015. https://fagarkivethioa.archive.knowledgearc.net/bitstream/handle/20.500.12199/3448/ Nettversjon-Rapport-10-15-ny.pdf?sequence=1\&isAllowed=y.

10. Bauldry S, Szaflarski M. Immigrant-based disparities in mental health care utilization. Socius. 2017;3:1-14.

11. Lindert J, Schouler-Ocak M, Heinz A, Priebe S. Mental health, health care utilisation of migrants in Europe. Eur Psychiatry. 2008;23(Supplement 1):14-20.

12. Vrålstad S, Wiggen KS. Levekår blant innvandrere i Norge 2016 [living conditions among immigrants in Norway 2016]: Statistics Norway; 2017. https://www.ssb.no/sosiale-forhold-og-kriminalitet/artikler-og-publikasjoner/_ attachment/309211.

13. Sarría-Santamera A, Hijas-Gómez Al, Carmona R, Gimeno-Feliú LA. A systematic review of the use of health services by immigrants and native populations. Public Health Rev. 2016;37(1):28.

14. World Health Organization. Depression and other common mental disorders. Global health estimates. 2017 1. September 2018.

15. Rickwood D, Thomas K. Conceptual measurement framework for help-seeking for mental health problems. Psychol Res Behav Manag. 2012;5:173-83.

16. Unrau YA, Grinnell RM. Exploring out-of-home placement as a moderator of help-seeking behavior among adolescents who are high risk. Res Soc Work Pract. 2005;15(6):516-30.

17. Andersen RM, Davidson PL. Improving access to care in America: Individual and contextual indicators. In: Anderson RM, Rice TH, KE F, editors. Changing the US health care system: key issues in health services, policy, and management. San Francisko: Jossey-Bass; 2001. p. 3-30.

18. Andersen RM. National health surveys and the behavioral model of health services use. Med Care. 2008;46(7):647-53.

19. Magaard JL, Seeralan T, Schulz H, Brütt AL. Factors associated with helpseeking behaviour among individuals with major depression: a systematic review. PLoS One. 2017;12(5):e0176730.

20. Doblyte $\mathrm{S}$, Jiménez-Mejías E. Understanding help-seeking behavior in depression: a qualitative synthesis of patients' experiences. Qual Health Res. 2016:27(1):100-13.

21. Yoon E, Chang C-T, Clawson A, Clearly SE, Hansen M, Bruner JP, et al. A meta-analysis of acculturation/enculturation and mental health. J Couns Psychol. 2013;60(1):15-30.

22. Berry JW. Immigration, acculturation, and adaption. Appl Psychol. 1997:46(1): 5-68

23. Sun S, Hoyt WT, Brockberg D, Lam J, Tiwari D. Acculturation and enculturation as predictors of psychological help-seeking attitudes (HSAs) among racial and ethnic minorities: a meta-analytic investigation. J Couns Psychol. 2016;63(6):617-32.

24. Rechel B, Mladovsky P, Devillé W. Monitoring migrant health in Europe: a narrative review of data collection practices. Health Policy. 2012;105(1):10-6.

25. Saint Arnault DM, Gang M, Woo S. Factors influencing on mental health help-seeking behavior among korean women: a path analysis. Arch Psychiatr Nurs. 2018;32(1):120-6.

26. Whitaker C, Stevelink S, Fear N. The use of Facebook in recruiting participants for health research purposes: A systematic review. J Med Internet Res. 2017:19(8):e290.

27. Ellard-Gray A, Jeffrey NK, Choubak M, Crann SE. Finding the hidden participant: solutions for recruiting hidden, hard-to-reach, and vulnerable populations. Int J Qual Methods. 2015;14(5):1609406915621420.

28. Pötzschke S, Braun M. Migrant sampling using facebook advertisements: a case study of polish migrants in four European countries. Soc Sci Comput Rev. 2016;35(5):633-53.

29. Faul F, Erdfelder E, Buchner A, Lang A-G. Statistical power analyses using $G^{*}$ power 3.1: tests for correlation and regression analyses. Behav Res Methods. 2009;41(4):1149-60.

30. Markova V, Sandal GM. Lay explanatory models of depression and preferred coping strategies among somali refugees in Norway. A mixed-method study. Front Psychol. 2016;7:1435.

31. World Health Organization. International classification of diseases. In: Mood disorders: Depressive episode. 10th ed; 2011. Available from: http://apps. who.int/classifications/apps/icd/icd10online/. 
32. Wilson CJ, Deane FP, Ciarrochi J, Rickwood D. Measuring help-seeking intentions: properties of the general help seeking questionnaire. Can J Couns Psychother. 2007;39(1):15-28.

33. Paulhus DL. Vancouver index of acculturation (VIA). Measurement instrument database for the social science 2013. Available from: http://www. midss.org/content/vancouver-index-acculturation.

34. Howard MC. A review of exploratory factor analysis decisions and overview of current practices: what we are doing and how can we improve? Int J Hum Comput Interact. 2016;32(1):51-62.

35. Tabachnick BG, Fidell LS. Using multivariate statistics. 6th ed. Boston: Pearson; 2013

36. Erdal K, Singh N, Tardif A. Attitudes about depression and its treatment among mental health professionals, lay persons and immigrants and refugees in Norway. J Affect Disord. 2011;133(3):481-8.

37. Brown JSL, Evans-Lacko S, Aschan L, Henderson MJ, Hatch SL, Hotopf M. Seeking informal and formal help for mental health problems in the community: a secondary analysis from a psychiatric morbidity survey in South London. BMC Psychiatry. 2014;14(1):275.

38. Luu TD, Leung P, Nash SG. Help-seeking attitudes among Vietnamese Americans: the impact of acculturation, cultural barriers, and spiritual beliefs. Soc Work Ment Health. 2009;7(5):476-93.

39. Givens JL, Houston TK, Van Voorhees BW, Ford DE, Cooper LA. Ethnicity and preferences for depression treatment. Gen Hosp Psychiatry. 2007; 29(3):182-91.

40. Kutcher S, Wei Y, Coniglio C. Mental health literacy: past, present, and future Can J Psychiatr. 2016:61(3):154-8

41. Wright A, Jorm AF, Mackinnon AJ. Labels used by young people to describe mental disorders: which ones predict effective help-seeking choices? Soc Psychiatry Psychiatr Epidemiol. 2012;47(6):917-26.

42. McClelland A, Khanam S, Furnham A. Cultural and age differences in beliefs about depression: British Bangladeshis vs. British whites. Ment Health Relig Cult. 2014;17(3):225-38.

43. Obasi EM, Leong FTL. Psychological distress, acculturation, and mental health-seeking attitudes among people of African descent in the United States: a preliminary investigation. J Couns Psychol. 2009;56(2):227-38.

44. Satinsky E, Fuhr DC, Woodward A, Sondorp E, Roberts B. Mental health care utilisation and access among refugees and asylum seekers in Europe: a systematic review. Health Policy. 2019;123:851-63.

45. Mellon J, Prosser $C$. Twitter and Facebook are not representative of the general population: political attitudes and demographics of British social media users. Res Polit. 2017;4(3):2053168017720008.

46. He J, Van de Vijver FJR. Bias and equivalence in cross-cultural research. Online Reading Psychol Cult. 2012;2(2):2307-0919.

47. Statistics Norway. Innvandrernes utdanningsnivå, 1.oktober 2001 [Immigrants level of education, 1. October 2001]. 2003.

48. Hanel PHP, Vione KC. Do student samples provide an accurate estimate of the general public? PLoS One. 2016;1 (12):e0168354-e.

49. Eurostat. Population by educational attainment level, sex and age (\%) main indicator - 2019. 2020.

50. European Commission/EACEA/Eurydice. The European Higher Education Area in 2018: Bologna process implementation report. Luxembourg: Publications Office of the European Union; 2018.

51. Sivertsen B, Råkil H, Munkvik E, Lønning KJ. Cohort profile: the SHoT-study, a national health and well-being survey of Norwegian university students. BMJ Open. 2019;9(1):e025200.

52. Stallman HM. Psychological distress in university students: a comparison with general population data. Aust Psychol. 2010:45(4):249-57.

\section{Publisher's Note}

Springer Nature remains neutral with regard to jurisdictional claims in published maps and institutional affiliations.

Ready to submit your research? Choose BMC and benefit from:

- fast, convenient online submission

- thorough peer review by experienced researchers in your field

- rapid publication on acceptance

- support for research data, including large and complex data types

- gold Open Access which fosters wider collaboration and increased citations

- maximum visibility for your research: over $100 \mathrm{M}$ website views per year

At $\mathrm{BMC}$, research is always in progress.

Learn more biomedcentral.com/submissions 